\section{Risky business}

\author{
Christina T. Mora Mangano, MD
}

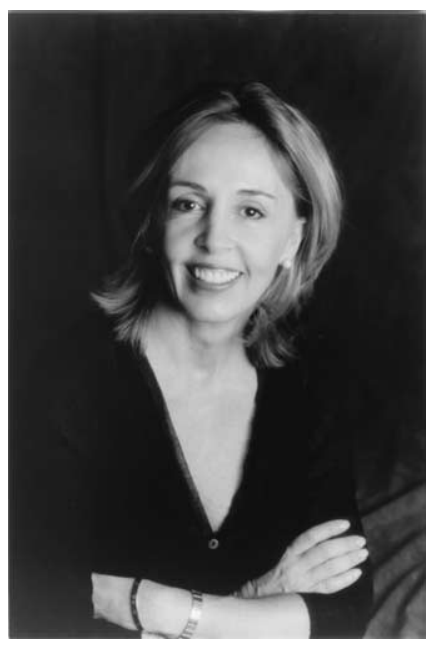

See related articles on pages 1394,1401 , and 1526.
From the Department of Anesthesia, Stanford University School of Medicine, Stanford, Calif.

Received for publication Jan 17, 2003; accepted for publication Jan 22, 2003.

Address for reprints: Christina Mora Mangano, MD, Stanford University Hospital, Department of Anesthesia, 300 Pasteur Dr, H3577, Stanford, CA 94305 (E-mail: cmoraman@stanford.edu).

J Thorac Cardiovasc Surg 2003;125:1204-7

Copyright (C) 2003 by The American Association for Thoracic Surgery

$0022-5223 / 2003 \$ 30.00+0$

doi:10.1016/S0022-5223(03)00573-7

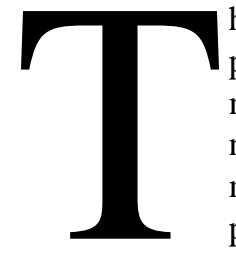

he ubiquitous media coverage of health care issues provides the patient, as consumer, with a plethora of information (and disinformation) for consideration. For example, casual investigation by a nonphysician will identify a variety of fundamentally different treatment options for ischemic heart disease. Strategies centered on pharmacologic therapy, angioplasty, coronary stents, or drug-eluting stents all have advocates and detractors. And although the prevalence of surgical coronary revascularization declined approximately $15 \%$ from 2000 to 2002, the proliferation of "new and improved" operative techniques - warm heart, minimally invasive, beating heart surgery-continues unfettered by rigorous scientific study. In contrast to new drugs, surgical innovation is adopted without peer or patient advocate review. Market forces persuade hospital administrators and push clinicians to adopt the latest surgical fashion to appease ever more "informed" patients. Marketing is increasingly more important than outcomes research.

In this issue of the Journal, two institutions share their individual experiences with another permutation of surgical revascularization techniques, and thus expose the patient to a new seduction or marketing tool: awake heart surgery. ${ }^{1,2}$ The patient may be persuaded that heart surgery is now so safe, so noninvasive, so trivial a challenge, that general anesthesia is no longer required. Referring physicians may conclude that the stress and recovery profiles associated with surgical coronary revascularization are similar to that of angioplasty, but now their patients can enjoy brand new conduits!

Aybek and associates, ${ }^{1}$ and Karagoz and colleagues, ${ }^{2}$ separately argue that their successful series of 34 and 137 awake CABG procedures, respectively, combine the "obvious" advantages of beating-heart surgery, and an anesthetic technique that provides analgesia in an awake, spontaneously breathing patient. In a previous Journal editorial (“Off-Pump Coronary Bypass: Is It for Everybody?"), Bonchek ${ }^{3}$ successfully debunked the notion that beating-heart surgery is obviously superior to a "remarkably successful, extensively studied, consistently reproducible procedure." The present editorial compares the theoretic risks and benefits (there are few data to assess, only theories) of three anesthetic approaches for cardiac surgery, with or without cardiopulmonary bypass (CPB): an awake, regional anesthetic with spontaneous respiration; general endotracheal anesthesia with controlled ventilation; or the latter augmented with a thoracic epidural neuroaxial block.

\section{Conscious Cardiac Surgery}

It is difficult, if not impossible, to recommend that a patient remain conscious during any type of cardiac surgical procedure. Advocates of regional techniques for cardiac surgery suggest (correctly) that spinal cord blockade attenuates the profound stress response associated with major surgery. ${ }^{4-6}$ However, one must consider the stress associated with consciousness during cardiac surgery. How will a patient respond to the intraoperative information that he has "poor distals" or to the surgeon's lament that the internal thoracic artery is inadequate? Even with absolute silence (and the inability to communicate verbally cannot facilitate the efficiency of an operation), most individuals are likely to suffer anxiety with the roar of a saw opening their chest. The mandate for spontaneous respiration limits the administration of sedativehypnotics and muscle relaxants. Finally, prescription of an anesthetic that allows a patient to move voluntarily during a cardiac procedure is anathema to the clinician committed to safety. Unanticipated patient movement may be merely inconvenient 
or may result in a disaster. At the 2002 autumn meeting of the Association of Cardiac Anesthesiologists (a group limited to 50 of the most senior cardiac anesthesiologists in the United States), not a single member advocated the use of a pure regional anesthetic technique for any type of cardiac surgery. The members opined that the more clinically important question relates to the use of regional anesthesia as a supplement to general endotracheal anesthesia techniques for heart surgery.

\section{Combined General and Thoracic Epidural Anesthesia}

The use of thoracic epidural anesthesia (TEA) as a supplement to general anesthesia and controlled ventilation may provide both intraoperative and postoperative benefits. Intraoperative palliative effects largely accrue from the sympatholysis associated with neuroaxial blockade ${ }^{4-7}$; postoperative benefits are a result of the profound analgesia afforded by TEA. ${ }^{8,9}$ Importantly, there are no randomized trials that characterize the risk-benefit profile of a neuroaxial block in cardiac surgery. However, several reports have demonstrated the clinical benefits associated with a reduction of circulating sympathoamines and other stress hormones. Four decades of clinical research have failed to find a general anesthetic technique that attenuates the stress response and resultant adverse sequelae associated with surgery and CPB. In contrast, spinal cord anesthesia-that is, the selective blocking of spinal nerve roots-prevents the surge in stress hormones that accompanies cardiac procedures. ${ }^{4-7}$ Perioperative sympatholysis improves myocardial oxygen supply-demand indices, attenuates platelet activation, and reduces the inflammatory cascade. The sympathetic nerve fibers from $\mathrm{T} 1$ to $\mathrm{T} 5$ innervate the myocardium and coronary vasculature and play a critical role in determining coronary blood flow and distribution. Blockade of the cardiac accelerator fibers may be responsible for the decreased prevalence of postoperative supraventricular tachycardias and other types of cardiac dysrhythmias observed in patients managed with a TEA. Thus the application of regional techniques as supplements to general anesthesia may be considered therapeutic as well as facilitative. Table 1 outlines the theoretic risks and benefits of a cardiac anesthetic technique that includes a regional component.

Neither the study of Aybek and associates ${ }^{1}$ nor that of Karagoz and colleagues ${ }^{2}$ assessed the potential therapeutic affects of an intraoperative neuroaxial blockade in their respective patients. Both sets of investigators allude to the potential benefits of a thoracic sympathectomy, but there are no measures of stress hormones, myocardial oxygen supplydemand determinants, or coronary blood flow distribution. Perioperative Holter monitor evidence of a reduction in myocardial ischemia or cardiac dysrhythmias would support the theory that spinal nerve blockade during coronary re-
TABLE 1. Regional anesthesia in the conscious cardiac surgical patient

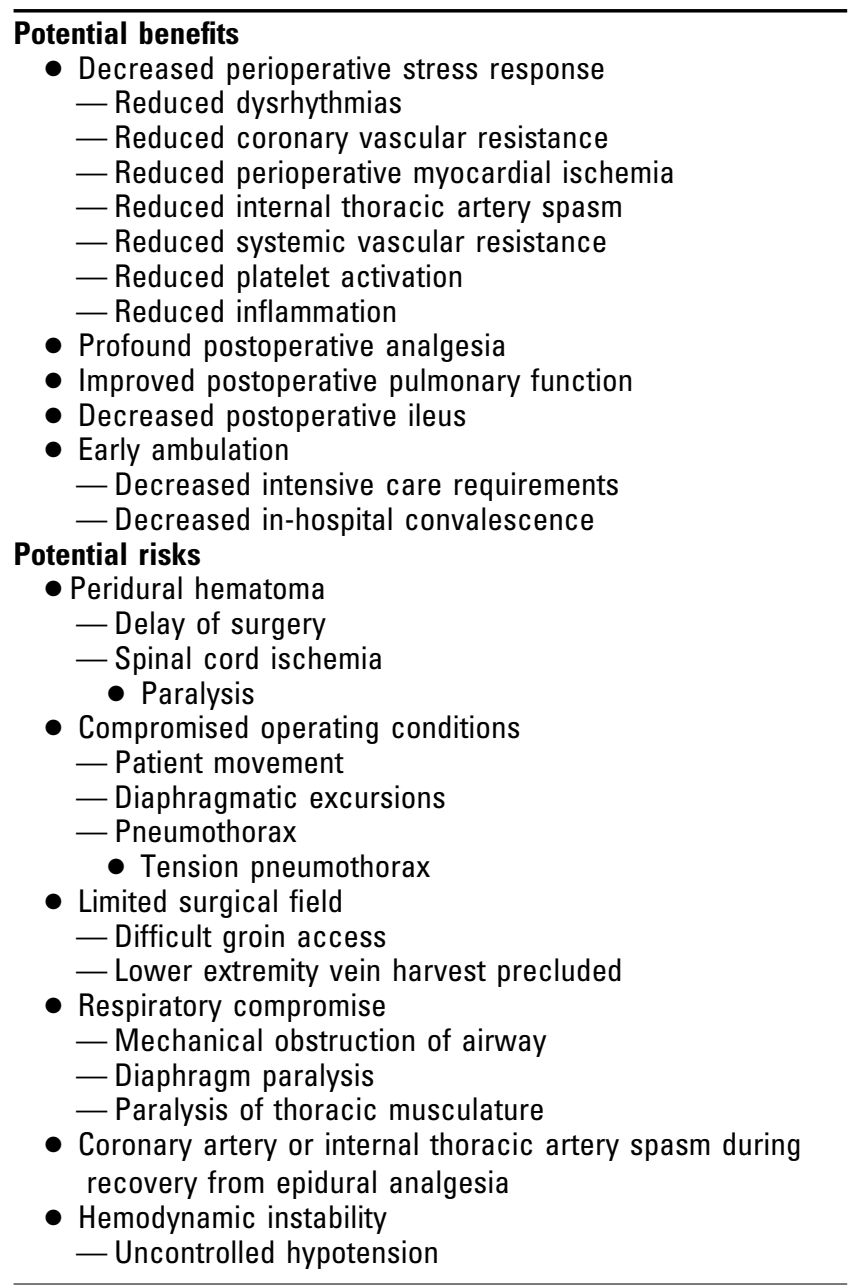

vascularization provides protection from these morbid events.

The reports of Aybek and associates ${ }^{1}$ and Karagoz and colleagues $^{2}$ emphasize the postoperative benefits of TEA. Indeed, several studies have demonstrated the superiority of epidural analgesia relative to conventional pain control techniques in patients recovering from cardiac surgery and median sternotomy. ${ }^{9}$ Superior analgesia leads to improved pulmonary function and early ambulation. ${ }^{10}$ This may allow reductions in the durations of both intensive care unit stays and hospital convalescence. Scott and coworkers ${ }^{9}$ prospectively randomly assigned 420 patients scheduled for elective coronary surgery and general anesthesia to receive TEA or be managed with conventional analgesic techniques. Patients managed with a preoperative TEA achieved endotracheal extubation more quickly, enjoyed superior respiratory function, and suffered fewer respiratory tract infections. Regulatory constraints limited the German group's ability to demonstrate a reduction in the duration of hospitalization ${ }^{1}$; 
however, Karagoz and colleagues revealed the promise of outpatient heart surgery, with 8 of their 132 patients $^{2}$ leaving the hospital on the same day as the procedure.

With many agreeing on the important benefits of neuroaxial blockade in cardiac surgery, ${ }^{11}$ why have TEA techniques failed to be widely adopted? Instrumentation of the epidural space may lead to unrecognized bleeding, hematoma formation, nerve root compression, ischemia, and paralysis. Unfortunately, the true prevalence of an epidural hematoma among patients requiring anticoagulation for heart surgery is unknown. Mathematic models suggest that the risk ranges from 1:150,000 to 1:1100. ${ }^{12}$ Advocates for regional techniques contend that there are no reports of an epidural hematoma causing paralysis in cardiac surgery. In a recent survey of cardiac anesthesiologists, however, some respondents refused to answer the questions regarding the local incidence of peridural hematomas; others stated that they had observed this complication in "other institutions." 13 Scott and coworkers" reported that none of their 202 patients suffered any adverse neurologic events associated related to the use of TEA. Careful review of studies reporting a zero incidence of epidural hematoma after TEA reveals ambitious, potentially time-consuming protocols to reduce the likelihood of epidural bleeding. The placement of the epidural catheter on the night before surgery, delaying surgery if a "bloody" tap occurs, and limiting epidural techniques to those patients not receiving preoperative anticoagulant drugs are strategies to limit the likelihood of peridural hematoma.

\section{Consciousness During CPB}

Of this month's trilogy of reports advocating consciousness during cardiac surgery, the article submitted by Schachner and colleagues ${ }^{14}$ is the most ambitious and alarming. This group placed an epidural block extending from spinal nerve levels $\mathrm{C} 7$ through $\mathrm{T} 8$ in a 70 -year-old man with aortic valve stenosis. Throughout the 4-hour procedure, the patient remained conscious and not paralyzed. During 123 minutes of normothermic CPB, the surgical team placed a $23-\mathrm{mm}$ biologic valve. The only reported difficulty was the negative impact of the "breathing pattern" on the "the surgical progress." Both the Aybek and Karagoz groups ${ }^{1,2}$ reported similar technical problems, which included incidences of pneumothorax of $10 \%$ and $28 \%$, respectively. In several instances, respiratory distress ensued and the patient required endotracheal intubation. Whereas the Schachner group ${ }^{14}$ contends that the delay in surgical progress was of minor consequence, one might argue that any elective intervention (and consciousness during CPB is not required) that prolongs the duration of $\mathrm{CPB}$ should be abandoned. And a longer than 2-hour period of CPB to replace an aortic valve certainly may be considered pro- tracted. Most anesthesiologists consider facilitation of "the surgical progress" an aspect of their clinical mandate. In some institutions, respiratory support includes manual control of tidal volumes and respiratory rates by the anesthesiologist during dissection of the mediastinum. The surgical staff believe that the operative conditions improve with "hand ventilation." Perhaps in an ideal world, the patient could be coached in breathing patterns to facilitate the surgical technique!

Schachner and colleagues ${ }^{14}$ suggest that an important advantage of caring for a conscious, rather than anesthetized, patient requiring CPB is the ability to monitor cerebral function continuously. Indeed, this group reports that they maintained oral communication with the patient throughout the procedure. However, I am unclear as to how they would respond to an apparent episode of cerebral ischemia. Would they induce general anesthesia and reduce cerebral temperature? Increase pump flow or perfusion pressure? Reconsider the placement of the aortic crossclamp? Look for the nearest hyperbaric oxygen chamber? In carotid artery procedures, the surgeon can amend the operative approach if a conscious patient has an acute manifestation of some type of cerebral impairment. In this setting, the cessation of carotid artery blood flow results in hemispheric cerebral hypoxemia. The placement of a shunt or increasing the pressure and collateral blood flow may obviate the acute ischemic insult. This is not the case in cardiac surgery, because the factors causing cerebral ischemia remain incompletely understood. The risks associated with consciousness during $\mathrm{CPB}$ are substantial. Potential serious adverse events range from patient movement leading to aortic cannula dislodgment and exsanguination to the prolongation of the duration of CPB. Because consciousness during CPB does not confer any identifiable benefit and the risks are life-threatening, there is no indication for an anesthetic technique that permits "awake" extracorporeal circulation.

In summary, the use of epidural techniques as adjuncts to general anesthesia in cardiac surgery merits further study. Although the risk is difficult to quantify, the substantial benefits associated with perioperative neuroaxial blockade mandates further investigation. Skeptics may be reassured by the finding of the limited morbidity associated with the placement of large subarachnoid catheters for cerebrospinal fluid drainage in patients requiring a thoracoabdominal procedure.

But awake heart surgery with spontaneous ventilation? There is no place for this trick in the cardiac anesthesiologist's armamentarium. Innovation is the religion of clinical science, but innovation simply for the sake of change (or marketing) will increase our patients' risks. Or as noted by the comedian Chris Rock, "Because you can steer a car with your feet, doesn't make it a good idea." 


\section{References}

1. Aybek T, Kessler P, Khan MF, Dogan S, Neidhart G, Moritz A, et al. Operative techniques in awake coronary artery bypass grafting. $J$ Thorac Cardiovasc Surg. 2003;125:1394-400.

2. Karagoz HY, Kurtoglu M, Bakkaloglu B, Sonmez B, Cetintas T, Bayazit K. Coronary artery bypass grafting in the awake patient: three years' experience in 137 cases. J Thorac Cardiovasc Surg. 2003;125: 1401-4.

3. Bonchek L. Off-pump coronary bypass: is it for everyone? J Thorac Cardiovasc Surg. 2002;124:431-4.

4. Kirno K, Friberg P, Grzegorczyk A, Milocco I, Ricksten SE, Lundin S. Thoracic epidural anesthesia during coronary artery bypass surgery: effects on cardiac sympathetic activity, myocardial blood flow and metabolism, and central hemodynamic. Anesth Analg. 1994;79:1075-81.

5. Loick HM, Schmidt C, Van Aken H, Junker R, Erren M, Berendes E, et al. High thoracic epidural anesthesia, but not clonidine, attenuates the perioperative stress response via sympatholysis and reduces the release of troponin $\mathrm{T}$ in patients undergoing coronary artery bypass grafting. Anesth Analg. 1999;88:701-9.

6. Moore CM, Cross MH, Desborough JP, Burrin JM, Macdonald IA, Hall GM. Hormonal effects of thoracic extradural analgesia for cardiac surgery. Br J Anaesth. 1995;75:387-93.

7. Rodgers A, Walker N, Schug S, McKee A, Kehlet H, van Zundert A, et al. Reduction of postoperative mortality and morbidity with epidural or spinal anaesthesia: results from overview of randomised trials. $B M J$. 2000;321:1493.

8. Warner D, Warner M, Ritman E. Human chest wall function during epidural anesthesia. Anesthesiology. 1996;85:761-73.

9. Scott N, Turfrey D, Ray D, Nzewi O, Sutcliffe N, Lal A, et al. A prospective randomized study of the potential benefits of thoracic epidural anesthesia and analgesia in patients undergoing CABG. Anesth Analg. 2001;93:528-33.

10. Tenling A, Joachimsson P, Tyden H, Hedenstieri G. Thoracic epidural analgesia as an adjunct to general anesthesia for cardiac surgery: effects on pulmonary mechanics. Acta Anaesthesiol Scand. 2000;44: 1071-6.

11. Chancy MA. Epidural techniques for adult cardiac surgery. In: Chancy MA, editor. Regional anesthesia for cardiothoracic surgery. A Society of Cardiovascular Anesthesiologists monograph. Philadelphia: Lippincott Williams \& Wilkins; 2002. p. 59-79.

12. Ho A, Chung D, Joynt G. Neuraxial blockade and hematoma in cardiac surgery. Chest. 2000;117:551-5.

13. Goldstein S, Dean D, Kim SJ, Cocozello K, Grofsik J, Silver P, et al. A survey of spinal and epidural techniques in adult cardiac surgery. J Cardiothorac Vasc Anesth. 2001;15:158-68.

14. Schachner T, Bonatti J, Balogh D, Margreiter J, Mair P, Laufer G, et al. Aortic valve replacement in the conscious patient under regional anesthesia without endotracheal intubation. J Thorac Cardiovasc Surg. 2003;125:1526-7.

\section{JTCVS On-Line Manuscript Submission and Review}

\section{Please visit http://www.editorialmanager.com/jtcvs/}

Effective September 15, 2001, authors and reviewers may submit manuscripts and reviews electronically via Editorial Manager, our new Web-based system with full electronic submission, review, and status update capabilities.

As we move from paper to electronic submissions, the Editorial Office will make proxy submissions of all manuscripts accompanied by a diskette containing the electronic files of the text, tables, and figures. Editors, authors, and reviewers will receive automatic e-mails when significant events occur.

We strongly encourage all authors and reviewers to use Editorial Manager. Although we will continue to accommodate the submission of paper manuscripts for some months, our goal is to be completely electronic within 9 to 12 months.

All individuals currently in our database for whom we have e-mail addresses will receive via e-mail a system-assigned username and password that can be used to log in to the system without prior registration. All those not receiving the e-mail must register the first time they use the system.

As with any broad systemic change, the conversion to the new system will take some time to complete. We ask your patience as we replace our in-office database with the new system. We also encourage you to take advantage of the speed and efficiency that the new system will provide for us all: editor, author, reviewer, and publisher. 